\title{
Segregação ocupacional no mercado de trabalho segundo cor e nível de escolaridade no Brasil contemporâneo
}

Occupational segregation in the labour market according to skin colour and level of schooling in contemporary Brazil

\author{
Rosana Ribeiro \\ Universidade Federal de Uberlândia \\ Guilherme Silva Araújo \\ Departamento Intersindical de Estatística e Estudos \\ Socioeconômicos de São Paulo
}

\section{Abstract}

The aim of this article is to analyze occupational segregation according to skin colour and level of schooling between 2002 and 2012. Occupational segregation is measured by indexes. These indexes show a bigger occupational segregation between white and black women than between white and black men, although this differential decreased during the time period. However, the levels of occupational segregation between white and black men who had fifteen years, or longer, of education increased, while the levels between black and white women decreased. It must be emphasized that most management positions are held by men. This result arouses concern. Moreover, the levels of occupational segregation between males according to skin colour and schooling level do not decrease, despite the increase of black males with higher schooling. The implementation of affirmative actions as well as quality improvement in education may contribute to the mitigation of this occupational segregation.

\section{Keywords}

labour market segregation; ethnicity; educational levels.

JEL Code J710.

\section{Resumo}

O propósito deste artigo é analisar a segregação ocupacional segundo cor e nivel de escolaridade no periodo de 2002 a 2012. A segregação ocupacional é mensurada por meio dos indices. Esses indices revelam maior segregação ocupacional entre brancas ou negras do que entre negros ou brancos, apesar de que esse diferencial se reduziu no intervalo temporal. Contudo, os patamares de segregação ocupacional entre brancos ou negros que têm 15 anos ou mais de estudo se elevaram, ao passo que, entre negras ou brancas, se reduziram. Vale ressaltar que a maioria das pessoas que exerce cargo de dirigentes são homens. Ou seja, esse resultado é no mínimo preocupante. Ademais, o patamar de segregação ocupacional entre pessoas do sexo masculino - brancos ou negros com maior nivel de escolaridade - não se reduz, embora a proporção de homens negros mais escolarizados se elevou. A adoção de ações afirmativas no mercado de trabalho brasileiro, bem como a melhora da qualidade da educação, poderia contribuir para mitigar essa segregação ocupacional.

\section{Palavras-chave}

segregação no mercado de trabalho; cor; nivel de escolaridade.

Código JEL J710. 


\section{Introdução}

O termo "segregação" no mercado de trabalho significa uma assimetria na contratação de trabalhadores pelas empresas, baseada em certas características, como sexo, cor, nacionalidade e qualificação profissional (Bahia et al., 2009). Consequentemente, isso induz a uma tendência de concentração dos trabalhadores em segmentos distintos, tendendo à formação de setores e guetos ocupacionais.

Em geral, os estudos nessa temática se concentram na análise da segregação por grupos ocupacionais (dirigentes, técnicos de nível médio, etc.). O título ocupacional se mostra um bom indicador do status socioeconômico dos trabalhadores; no entanto, outras informações, como nível de renda e de escolaridade, são igualmente importantes para apreensão desse status. Alguns estudiosos consideram tais variáveis em suas pesquisas acerca das desigualdades existentes entre os trabalhadores brasileiros (Silva, 2003; Ribeiro, 2003). Neste artigo, optamos pelo estudo da segregação ocupacional segundo sexo, cor e nível de escolaridade. O recorte temporal abarca o período de 2002 a 2012. A opção por esse intervalo se deve aos limites de comparação temporal das informações obtidas com base nos microdados da Pesquisa Nacional de Amostra de Domicílios (PNAD)/Instituto Brasileiro de Geografia e Estatística (IBGE), visto que, no ano de 2002, novo esquema classificatório para os títulos ocupacionais foi adotado. Outro motivo para a escolha desse recorte temporal se deve aos riscos que estudos que buscam mensurar a segregação ocupacional segundo a cor experimentam, caso considerem extenso período. Isso porque na PNAD a identificação da cor dos indivíduos se baseia na autodeclaração, a qual se altera no tempo, sobretudo se considerarmos que os movimentos sociais atuaram no passado recente no intuito de despertar a tomada de consciência por parte da população sobre seus valores.

Vale observar que utilizamos os novos pesos estimados pelo IBGE para pessoas que compõem a amostra da PNAD valendo-nos dos resultados do Censo Demográfico de 2010. As estimativas dos índices de segregação ocupacional se concentram em assalariados com carteira de trabalho assinada com mais de 23 anos, e que trabalham acima de 39 horas semanais. A diversidade do processo de seleção entre trabalhadores incluídos na Consolidação das Leis Trabalhistas (CLT) e aqueles que se inserem no regime estatutário é o principal motivo para nos concentrarmos nos assalariados 
com carteira de trabalho. A partir da promulgação da Constituição Federal de 1988, o acesso ao posto de trabalho no regime de estatutário se realiza via concurso público, enquanto no setor privado o processo de seleção é inteiramente distinto. Obviamente, as pessoas aptas aos concursos públicos evidenciam a existência de uma pré-seleção; no entanto, nossa meta neste artigo é analisar a segregação ocupacional entre os assalariados com carteira de trabalho no passado recente.

A segregação ocupacional pode ser definida como a maior presença de brancos ou negros em distintos grupos ocupacionais. Essa distribuição pode se alterar no tempo, porém uma elevada proporção de trabalhadores de cor diferente permanece concentrada em distintos grupos ocupacionais. Muitas vezes, nota-se que a segregação ocupacional impõe uma concentração de indivíduos, em razão de sua cor, em grupos ocupacionais de baixos rendimentos (Oliveira, 1997; Araújo; Ribeiro, 2002). Por outro lado, estudamos a segregação no mercado de trabalho também segundo grupos de anos de estudo, na medida em que o nível de escolaridade estabelece limites para a inserção dos trabalhadores em certos grupos ocupacionais, como o de dirigentes, que exigem determinado patamar mínimo de conhecimento formal. A qualificação da força de trabalho envolve vários componentes, como o conhecimento formal (escolaridade), o conhecimento adquirido no local de trabalho (experiência), os hábitos e as atitudes. Deste modo, o nível de escolaridade dos trabalhadores é somente uma proxy da qualificação.

Este estudo também se concentra na população branca e negra (pretos e pardos). Em relação à renda, a população preta e parda se assemelha, e, assim, optamos por juntá-los tal como em vários estudos (King, 2009).

Cabe observar que vários estudos se dedicam à discriminação no mercado de trabalho segundo gênero; porém, algumas distinções podem ser realizadas entre os termos "segregação" e "discriminação". O termo "discriminação" se refere às situações em que indivíduos igualmente produtivos são avaliados diferentemente a partir de atributos não produtivos (como gênero e cor). De acordo com Becker (1957), a discriminação se verifica quando um grupo (empregadores, trabalhadores, consumidores) considera que o contato com outro grupo provoca desutilidade/desprazer que se origina do preconceito ou da ignorância. Desse modo, o empregador opta por não contratar trabalhadores do grupo discriminado em razão de seu preconceito e somente aceita admitir tais trabalhadores por salários menores que aquele pago ao grupo não discriminado. $O$ salário menor do 
grupo discriminado se deve, portanto, à produtividade do trabalho menor desse grupo visto que gera maior desutilidade no trabalho. Já a discriminação se deve à atitude consciente do empregador (consumidor ou trabalhador), que algumas vezes se recusa a empregar determinados trabalhadores em virtude de seus atributos não produtivos. A discriminação no mercado de trabalho pode resultar ou provocar a "segregação" no trabalho, e o inverso também é provável. Em geral, entende-se "segregação" como uma situação, por exemplo, em que brancos e negros permanecem concentrados em diferentes grupos de ocupação de forma diversa à sua participação na composição da população por vários motivos, como razões culturais, geográficas, modos e hábitos estabelecidos, etc. As ocupações integradas são aquelas que têm participação semelhante de brancos e negros em relação à sua participação na população total, enquanto as ocupações segregadas são aquelas que exibem representações de negros e brancos consideravelmente divergentes da participação relativa desses grupos na população.

À guisa de ilustração, a "segregação" ocupacional entre homens e mulheres pode ser observada através da elevada participação de indivíduos de determinado sexo em certos grupos ocupacionais, e em geral as mulheres se concentram naqueles de menor rendimento em relação aos homens. Em 2002, no intuito de captar a segregação ocupacional entre mulher e homem, estimamos o valor do Índice de Dissimilaridade de Duncan \& Duncan (D), que correspondeu ao valor de 0,33, enquanto em 2012 esse índice se elevou para 0,36 . Ou seja, o índice revela a existência de segregação ocupacional entre homens e mulheres, bem como sua elevação no mesmo período. Não se constitui nosso propósito compreender os determinantes dessa elevação, visto que optamos neste artigo pela análise dessa segregação segundo cor e nível de escolaridade entre as pessoas do sexo feminino ou masculino. Esse recorte se deve às divergências que surgem à medida que um homem com 15 anos de estudo e uma mulher que tem 4 anos de estudo se inserem no mercado de trabalho. Ao cotejarmos o atributo nível de escolaridade dessas pessoas, podemos aguardar divergências nos postos de trabalho e nos respectivos rendimentos obtidos por esses indivíduos. Ao analisar a segregação ocupacional existente em cada grupo de homem branco ou negro, bem como no grupo no grupo de mulher negra ou branca segundo nível de escolaridade, buscamos tornar mais homogêneo alguns atributos produtivos como nível de escolaridade e salientar diferenças a partir de atributos não produtivos como cor. 
É possível existir um cenário de segregação ocupacional entre homens e mulheres sem que se verifique necessariamente discriminação, na medida em que a distribuição de trabalhadores em distintos grupos ocupacionais, segundo gênero, se origine dos fatores típicos da segregação, quais sejam: razões históricas, preferência dos trabalhadores por determinado tipo/grupo ocupacional, motivos culturais, ou estrutura econômica regional. No entanto, é comum a combinação da segregação e da discriminação no mercado de trabalho, à medida que a discriminação impõe aos grupos menos favorecidos, como mulheres, concentração em grupos ocupacionais com menores rendimentos. Deste modo, o processo de discriminação é capaz de induzir ou aumentar a situação da segregação ocupacional.

Grande parte da literatura acerca dos estudos de discriminação e segregação segundo grupos ocupacionais se dedica aos diferenciais existentes entre os gêneros. Assim, as divergências, sobretudo em remuneração e inserção no mercado de trabalho de homens e mulheres, são analisadas por diversas pesquisas (Oliveira, 1997; Araújo; Ribeiro, 2002). O tema segregação ocupacional entre os trabalhadores segundo sexo, cor e nível de escolaridade reúne parcas reflexões. Por outro lado, estudos sobre segregação ocupacional se revelam importantes na medida em que possam contribuir com a formulação de políticas públicas e reduzi-la de forma efetiva. $\bigcirc$ objetivo deste artigo é analisar as mudanças e a continuidade nessa segregação entre negros e brancos, segundo grupos ocupacionais e nível de escolaridade, bem como entre negras e brancas. Nosso pressuposto é que houve mudança no patamar de segregação, na medida em que a estrutura econômica se modificou no período, a urbanização e os costumes se alteraram, além do que o nível de escolaridade passou de uma média de 5,2 anos de estudo, para homens que têm 15 anos ou mais de idade em 1992, para uma média de 7,7 anos de estudo em 2012, ao passo que, para mulheres com 15 anos ou mais de idade, passou de 5,3 anos de estudo em 1992, para 8,1 anos de estudo em 2012. O maior nível de escolaridade gera a possibilidade de acesso da população pouco escolarizada a postos de trabalhos mais qualificados e bem remunerados, embora a maior escolaridade, isoladamente, não assegure a concretização dessa oportunidade.

Este artigo contém quatro seções, além desta introdução. A primeira seção versa sobre as contribuições dos economistas acerca das origens da discriminação e da segregação no mercado de trabalho, e a segunda se dedica a uma análise dos estudos em níveis internacional e nacional que 
buscaram mensurar a discriminação e a segregação no mercado de trabalho brasileiro no passado recente. A terceira seção compreende análise dos Índices de Dissimilaridade de Duncan \& Duncan (D), Dissimilaridade Padronizado pelo Tamanho (Ds) e Karmel-MacLachlan (KM), enquanto, na quarta seção, estudamos as transformações desses índices segundo trabalhadoras negras e brancas, bem como entre trabalhadores negros e brancos no período de 2002-2012. Por fim, as notas conclusivas.

\section{Discriminação ou segregação no mercado de traba- Iho: ponderações teóricas}

Os economistas buscaram desenvolver modelos explicativos para o fenômeno da discriminação no mercado de trabalho, contudo praticamente inexistem modelos que tratam separadamente o tema segregação no trabalho. $\mathrm{Na}$ introdução, definimos "discriminação" e "segregação" no mercado de trabalho e visualizamos a estreita articulação entre esses conceitos. Desse modo, optamos por analisar os modelos que versam sobre discriminação no trabalho, visto que notamos essa estreita relação. Os estudos iniciais sobre os temas de discriminação no mercado de trabalho buscavam investigar os determinantes dos diferenciais de rendimentos à medida que o modelo de concorrência pura prevê que tais hiatos serão eliminados embora persistam nos dias atuais. Ao recortar o mercado de trabalho em dois grupos de trabalhadores qualificados e pouco qualificados, ainda assim se notam entre indivíduos com idênticos atributos produtivos (tais como nível de escolaridade e experiência laboral) diferenciais de salário. Esses hiatos seriam explicados pelos atributos não produtivos como sexo ou cor dos trabalhadores?

Os estudos pioneiros nas ciências econômicas acerca da segregação no mercado de trabalho são elaborados por economistas ingleses e americanos. Uma das primeiras obras dedicadas ao tema da discriminação/ segregação foi de Edgeworth (1923) nos anos 1920 (Chadarevian, 2009). Cabe lembrar que, a partir da década de 1940, o movimento negro americano questiona a segregação racial existente naquele mercado de trabalho. Transcorridos mais de trinta anos da publicação da obra de Edgeworth (1923), o tema retorna à agenda de pesquisa dos economistas. Becker (1957) realizou estudo importante sobretudo em relação à discriminação no mercado de trabalho na tentativa de estudar seus determinantes ainda 
que seja inegável a articulação existente entre segregação e discriminação no trabalho. Essa teoria se baseia nos princípios do individualismo metodológico desenvolvidos pela economia neoclássica. Segundo essa abordagem, os indivíduos são considerados sujeitos racionais e bem informados sobre a sociedade em que vivem. Na perspectiva do individualismo metodológico, o entendimento do funcionamento do sistema econômico exige o conhecimento do comportamento que orienta as decisões individuais dos agentes e, portanto, de aspectos da microeconomia. Dessa forma, com base nas decisões individuais, esse autor busca explicar os diferenciais de salário entre pessoas com atributos produtivos semelhantes e vincular tais hiatos de remuneração aos cálculos de custos e benefícios que caracterizam o indivíduo racional. O grande desafio que Becker (1957) enfrentava no período seria justificar a aparente irracionalidade dos empregadores em não contratar trabalhadores não brancos com menores salários, em vez de admitirem brancos com maiores salários. $\bigcirc$ autor atribuiu esses diferenciais aos distintos graus de desutilidade dos trabalhadores dos grupos discriminados e não discriminados que se originam dos preconceitos dos indivíduos contra grupos como mulheres, negros, etc. Vale dizer, diferentes níveis de desutilidades conduzem a distintos salários entre os grupos de trabalhadores, visto que existiriam diversos resultados de produtividade do trabalho. Os diferenciais de salário obedeceriam ao cotejo entre custo e benefício de cada trabalhador, e, portanto, o grupo discriminado teria maior custo na medida em que gera maior desutilidade e receberia menor salário. Essa justificativa sustenta a lógica dos agentes racionais em busca da maximização da utilidade (consumidor) ou do lucro (empresário).

Além do que Becker (1957) investigou, há algumas fontes de discriminação no mercado de trabalho. A primeira fonte compreende o preconceito pessoal e pode ser notada quando empregadores resistem em desenvolver as atividades de trabalho com alguns grupos como mulheres. Esse preconceito pessoal pode também resultar dos empregados e dos consumidores. A segunda fonte é proveniente do preconceito estatístico que se refere à projeção que os empregadores realizam nos indivíduos a partir de alguns traços de grupo. Há ainda a terceira fonte de discriminação, mencionada por estudiosos como Cain (1976), que resulta do poder de monopólio.

Por outro lado, Becker (1957) elaborou também modelos associados com algumas das fontes de discriminação. À guisa de ilustração, optamos pelo modelo da discriminação do empregador, que parte do suposto que 
esses sejam homens brancos e resistem em admitir em suas empresas indivíduos do grupo discriminado (mulheres, homens negros, etc.), mesmo que esses trabalhadores tenham atributos produtivos idênticos aos candidatos ao trabalho que são homens e brancos. A motivação do empregador em preferir os homens brancos na contratação de trabalhadores pode ser oriunda de considerações sobre o status e conduzir a segregação ocupacional em determinados grupos. Mais uma vez, a discriminação no mercado de trabalho e a segregação ocupacional têm estreita vinculação. O modelo de Becker (1957), baseado no raciocínio da maximização dos lucros dos empregadores, aponta que existe uma explicação econômica para o preconceito porque a produtividade real dos grupos discriminados é desvalorizada pelos empregadores; então, esses trabalhadores devem aceitar salários menores em relação aos homens brancos para competirem no mercado de trabalho. Um questionamento apontado valendo-se desse modelo seria se o resultado conduziria à maximização da utilidade ou à maximização dos lucros (Ehrenberg; Smith, 2000).

O modelo de discriminação estatística, por sua vez, baseia-se no suposto que os empregadores não podem avaliar com precisão a produtividade real do trabalho dos candidatos ao emprego (Aigner; Cain, 1977). Os empregadores são cientes das imperfeições dos testes de contratação e adicionam elementos subjetivos, tais como informações dos grupos (mulheres, negros, etc.) dos candidatos, nesse processo que poderia, então, se parecer com a discriminação. Nesse caso, a discriminação resultaria de uma imperfeição na distribuição de informações. Esses argumentos também podem ser utilizados para a segregação ocupacional. Conforme Olson (1990, p.161):

De acordo com esta teoria, a segregação ocupacional resulta de informação imperfeita sobre os candidatos a um emprego durante o processo de seleção. Para empresas com custos substanciais de contratação e treinamento, a informação incompleta sobre os candidatos pode levar a um erro caro. Portanto, empregadores avessos ao risco 'discriminam estatisticamente'.

A previsão do modelo de discriminação estatística seria o desaparecimento da discriminação estatística, na medida em que as diferenças não quantificáveis dentro dos grupos discriminados se elevem ao longo do tempo.

A terceira linhagem de modelos se refere ao poder do monopólio que atribui a persistência da discriminação aos lucros obtidos pelos empregadores. A força de trabalho seria dividida em grupos competitivos e não competitivos, perpetuando um sistema de casta que impediria as forças competitivas de atuarem no mercado de trabalho. As versões mais conhe- 
cidas desses modelos são saturação, mercados de trabalhos duplos e ação de conluio (Madden, 1973). Nos modelos de saturação, mesclam-se a discriminação e a segregação ocupacional e verifica-se, por exemplo, a existência de dois mercados de trabalho diferenciados pelo tamanho da oferta de trabalhadores. Se partirmos de um patamar de oferta agregada de trabalho (curva de oferta positivamente inclinada) elevado em relação ao nível de demanda agregada de trabalho (curva demanda negativamente inclinada), o resultado seria um nível de salário menor do que no caso de uma oferta de trabalho mais reduzida e demanda de trabalho elevada. Essa perspectiva busca, a partir da saturação ou não no mercado de trabalho, estimar os diferenciais de salários embora não exista nesses modelos uma explicação para segregação que na verdade é atribuída aos costumes sociais, etc.

No caso dos modelos de mercados de trabalhos duplos que correspondem aos mercados primário e secundário (Gordon et al., 1982). O mercado primário seria caracterizado por empregos estáveis, bons salários e boas condições de trabalho, enquanto o secundário teria empregos instáveis e remuneração reduzida. A mobilidade dos trabalhadores entre esses mercados de trabalho seria reduzida, e, portanto, perpetuar-se-iam os diferenciais de salário que não seriam resolvidos pelas forças de mercado. No entanto, novamente não existe uma explicação, no próprio modelo, dos motivos para divisão (segregação) inicial em grupos do mercado de trabalho.

Em relação às abordagens incluídas na ação de conluio, encontram-se aquelas que se baseiam no argumento que os empregadores brancos entram em conluio e se tornam monopsonistas em relação ao processo de contratação dos grupos discriminados (Thurow, 1969). Os preconceitos e os conflitos no mercado de trabalho são de interesse dos empregadores visto que os detentores das empresas podem contratar os trabalhadores dos grupos discriminados por menores salários. Contudo, a discriminação e a segregação se verificam em sociedades não capitalistas; além disso, os estudiosos não apontam como o conluio é coordenado entre vários empregadores.

As distintas fontes de discriminação (segregação) podem contribuir para gerar ou elevar a segregação (discriminação) no mercado de trabalho; no entanto, os economistas não desenvolveram modelos teóricos que lancem luz acerca dos principais motivos da origem da discriminação e/ou da segregação no mercado de trabalho. Em geral, os economistas utilizam fatores explicativos mencionados em outras ciências como costumes sociais, processo histórico, etc. 


\section{Literatura internacional e nacional sobre segrega- ção no mercado de trabalho}

Nesta seção opta-se pelo estudo de textos que versam sobre a segregação no mercado de trabalho visto que nosso objetivo é investigar a segregação ocupacional em nosso país. Realizamos exaustivo levantamento dos estudos acerca da segregação ocupacional na literatura internacional; no entanto, encontramos um artigo que estima essa segregação por meio do Índice de Dissimilaridade de Duncan \& Duncan para os Estados Unidos da América. Em geral, esse país é conhecido por sua intensa discriminação e segregação racial, que resultaram em vários conflitos no século passado, entre os anos 1940 a 1960. Albelda (1986) analisou o mercado de trabalho americano para 1958 e 1981, no intuito de estimar o nível de segregação. O autor segmentou os trabalhadores em oito grupos: homens brancos, mulheres brancas, homens não brancos, mulheres não brancas, homens, mulheres, brancos e não brancos. $\bigcirc$ valor do Índice de Dissimilaridade de Duncan \& Duncan entre mulheres brancas e não brancas passou de 49,9\%, em 1958, para $17,2 \%$, em 1981. Vale dizer, nesse período, a variação relativa nesse índice atingiu - 65,5\%. O Índice de Dissimilaridade de Duncan \& Duncan entre homens brancos e não brancos, em 1958, foi de $40 \%$, ao passo que, no ano de 1981, seu valor se reduziu para $23,8 \%$. Dessa forma, a segregação ocupacional segundo cor se reduziu entre pessoas do sexo masculino e feminino. Albelda (1986) também apontou que a segregação ocupacional segundo gênero também se reduziu no mesmo período, embora a queda na segregação por cor se revele mais significativa do que a redução na segregação segundo gênero. Além disso, o autor estimou regressões em que o Índice de Dissimilaridade correspondeu à variável dependente, enquanto as variáveis independentes compreenderam o nível de escolaridade, ciclo de negócios (utilizando a taxa geral de desemprego) e tendência temporal. Esse teste estatístico revelou que o nível de escolaridade e o ciclo de negócios contribuem significativamente para a redução da segregação ocupacional segundo cor, embora não se revelem importante para a diminuição dessa segregação por sexo. Albelda (1986) realça que as políticas públicas que visem reduzir a taxa de desocupação são decisivas para uma distribuição mais igualitária de pessoas brancas e não brancas nos grupos ocupacionais, visto que, nas crises econômicas, os trabalhadores negros são os primeiros a ser demitidos ou a ter seus rendimentos diminuídos. 
No caso brasileiro, Barros et al. (2001) analisaram os microdados da Pesquisa Mensal de Emprego (PME) em 1996, 1997 e 1998. O objetivo desse estudo é estimar os impactos das medidas de bem-estar e de capacidade de geração de renda por meio de alteração da inserção das mulheres no mercado de trabalho. A metodologia utilizada para captar o efeito da mudança da inserção da mulher no mercado de trabalho consiste em exercícios contrafactuais não paramétricos, por meio dos quais as mulheres têm chances semelhantes àquelas dos homens no mercado de trabalho. Segundo os autores, as mulheres que têm, em média, nível educacional superior ao dos homens não conseguem melhores oportunidades de emprego.

Ademais, Barros et al. (2001), no intuito de atingir seus propósitos, utilizaram vinte diferentes grupos ocupacionais e verificaram que, em doze desses grupos, se constata participação das mulheres distinta da proporção dessas pessoas na população ocupada, e, assim, nota-se a presença da segregação ocupacional. No mais, os grupos ocupacionais com maior taxa de participação feminina absorvem $80 \%$ do total das mulheres que estão no mercado de trabalho, enquanto, no caso dos homens, esses grupos ocupacionais empregam $40 \%$ do total de homens na força de trabalho. Os autores concluíram, surpreendentemente, que a melhora no padrão de inserção feminina no mercado de trabalho tem efeitos bastante limitados sobre o bem-estar familiar.

Outro estudo acerca do tema da segregação no mercado de trabalho brasileiro com enfoque regional é realizado por Araújo e Ribeiro (2002). Esses autores analisam os hiatos de rendimentos entre mulheres e homens nas diversas regiões brasileiras por meio dos microdados da PNAD no ano de 1995. Os grupos ocupacionais, com base em estimavas do Índice de Dissimilaridade de Duncan \& Duncan e do Índice de Dissimilaridade Padronizado pelo Tamanho, são classificados em masculinos, femininos ou integrados. Esses cálculos são realizados para as regiões brasileiras, e nota-se maior segregação ocupacional no Nordeste do país. Por outro lado, o estudo das diferenças salariais segundo sexo se realiza por meio de Técnicas Empíricas de Decomposição. Esses testes, por sua vez, revelaram que os maiores diferenciais de rendimento por sexo se localizam nas regiões Sul e Sudeste, e os menores hiatos salariais são notados no Norte e Nordeste brasileiros. Outro resultado do estudo é o valor positivo do termo discriminação ocupacional para mulheres nas distintas regiões do país. 
Por outro lado, a análise de King (2009) se baseou no Índice de Dissimilaridade de Duncan \& Duncan para estudar o nível de segregação ocupacional no mercado de trabalho em nosso país entre homens brancos e negros, bem como entre mulheres negras e brancas. Os microdados são oriundos da PNAD no período de 1989 a 2001. Os resultados revelaram que as trabalhadoras negras concentram sua ocupação nos serviços domésticos e agrícolas, ao passo que a maioria das brancas exerce ocupações administrativas. No caso dos homens, os negros trabalham sobretudo em ocupações agrícolas e industriais, enquanto os trabalhadores brancos se concentram em ocupações administrativas e técnico-científico-artísticas. $O$ valor do Índice de Duncan entre mulheres negras e brancas nos anos 1989 e 2001 passou de 0,251 para 0,229, enquanto, no caso de trabalhadores negros e brancos, esses valores foram de 0,221 para 0,23 . Noutras palavras, a segregação ocupacional se reduziu entre as mulheres brancas e negras, mas entre trabalhadores negros e brancos se nota ligeira elevação dessa segregação, além do que os patamares de segregação são similares entre homens e mulheres segundo cor. De acordo com King (2009), a diferença no nível de escolaridade entre indivíduos brancos e negros contribui para a existência da segregação ocupacional; no entanto, no grupo de pessoas com nível elevado de escolaridade verifica-se também valor alto para o Índice de Dissimilaridade de Duncan \& Duncan.

Por outro lado, Cacciamali e Hirata (2005) estudam a discriminação contra os negros e as mulheres em terras paulistas e baianas. As autoras utilizaram os microdados da PNAD de 2002 e os dividiram em três grupos de trabalhadores: dirigentes e gerentes de empresas; empregados registrados; e empregados sem registro. Cacciamali e Hirata (2005) realizaram testes estatísticos por meio do modelo PROBIT e notaram que a discriminação segundo cor e sexo se verifica entre esses grupos de trabalhadores. Além disso, os testes não apontaram a existência de discriminação segundo cor entre os trabalhadores mais pobres; porém, persiste, no caso desses ocupados, a discriminação contra a mulher.

Um estudo mais recente que mescla discriminação e segregação no mercado de trabalho foi realizado por Cambota e Pontes (2007). Os autores investigam os diferenciais de rendimento existentes dentro do mesmo grupo ocupacional para trabalhadores negros e brancos. A amostra compreende oito grupos ocupacionais, tais como: dirigentes em geral; 
profissionais das ciências e das artes; técnicos de nível médio; trabalhadores administrativos; trabalhadores dos serviços; trabalhadores do comércio; trabalhadores agrícolas; e trabalhadores da produção de bens e serviços e manutenção. Os microdados utilizados são provenientes da PNAD do ano de 2004, enquanto a metodologia se baseia no método semiparamétrico de Dinardo, Fortin e Lemieux (1996), que, por sua vez, utiliza o estimador de núcleo. Os resultados indicam discriminação salarial contra as mulheres num mesmo grupo ocupacional, sobretudo naqueles grupos que exigem maior nível de escolaridade. Os autores verificam que não há, em todos os grupos ocupacionais, tendência de redução na razão entre o rendimento contrafactual das mulheres e o rendimento dos homens. Segundo Cambota e Pontes (2007), o mercado de trabalho estabelece limites ao acesso de pessoas do sexo feminino aos cargos de melhor remuneração e dificulta, portanto, a mobilidade social das mulheres e contribui para a feminização da pobreza. Ademais, os resultados sinalizam que hiatos de rendimentos entre homens e mulheres decorrem também de fatores não controlados.

\section{4 Índices de segregação ocupacional}

A seguir, analisamos alguns índices que permitem mensurar a segregação ocupacional entre mulheres brancas e negras, bem como entre homens negros e brancos segundo cor e nível de escolaridade.

\section{1 Índice de Dissimilaridade de Duncan \& Duncan (D)}

O propósito do Índice de Dissimilaridade de Duncan \& Duncan (D) é mensurar o grau de segregação. A título de ilustração, esse índice permite calcular a segregação ocupacional segundo o sexo - homens e mulheres - e segundo a cor - brancos e negros (Oliveira, 1997). A fórmula (1) ilustra o cálculo da segregação ocupacional entre homens negros e brancos:

$$
D=\left(\frac{1}{2}\right) \sum_{j=1}^{J}\left|\left(\frac{H N_{j}}{H N}\right)-\left(\frac{H B_{j}}{H B}\right)\right|
$$


onde:

$J$ = número total de ocupações;

$H N_{j}=$ número de indivíduos de um grupo (homens negros) na ocupação j; $H N=$ número de homens negros ocupados no mercado de trabalho total; $H B_{j}=$ número de indivíduos no grupo de comparação (homens brancos) na ocupação j;

$H B=$ número de homens brancos ocupados no mercado de trabalho total.

Valendo-nos desse índice, podemos mensurar a proporção de homens negros (ou brancos) que deveriam mudar de ocupação para que a proporção desses indivíduos em cada ocupação seja igual a sua participação na força de trabalho total. O resultado final dessas mudanças seria a eliminação da segregação ocupacional (Oliveira, 1997). O valor do índice D oscila entre zero e um. $\mathrm{Na}$ interpretação desses valores, 0 (zero) aponta perfeita integração dos grupos ocupacionais, enquanto o valor 1 corresponde à plena segregação ocupacional.

\section{2 Índice de Dissimilaridade Padronizado pelo Tamanho (Ds)}

O objetivo do Índice de Dissimilaridade Padronizado pelo Tamanho (Ds) também é mensurar a segregação. No caso desse, considera-se um número fixo de categorias ocupacionais comparáveis, e, portanto, os grupos de ocupação são tratados como se fossem do mesmo tamanho (Oliveira, 1997, 1998). A fórmula (2) corresponde ao cálculo do Índice de Dissimilaridade Padronizado pelo Tamanho (Ds):

$$
D_{s}=\left(\frac{1}{2}\right) \sum_{j=1}^{J} \llbracket\left[\frac{\left(\frac{H N_{j}}{T_{j}}\right)}{\sum_{j=1}^{J}\left(\frac{H N_{j}}{T_{j}}\right)}\right]-\left[\frac{\left(\frac{H B_{j}}{T_{j}}\right)}{\sum_{j=1}^{J}\left(\frac{H B_{j}}{T_{j}}\right)}\right]
$$

onde: = número total de homens negros e homens brancos no grupo ocupacional $j=H N_{j}+H B_{j}$; os numeradores $\frac{H N_{j}}{T_{j}}$ e $\frac{H B_{j}}{T_{j}}$ indexam as proporções de homens negros e homens brancos no grupo ocupacional j; e os 
denominadores ajustam tais valores sobre as proporções prevalecentes nos grupos ocupacionais (Oliveira, 1997, 1998).

Esse índice permite eliminar a dependência marginal estabelecida com a estrutura ocupacional ao atribuir pesos por meio da soma das proporções de cada cor nos diferentes grupos ocupacionais. Essa dependência é eliminada, visto que padroniza cada um dos grupos ocupacionais $j$ ao mesmo tamanho e, assim, não possibilita que as alterações no tamanho dos grupos ocupacionais, ao longo do tempo, impactem seu valor. Deve-se ressaltar que esse procedimento de ponderação produz uma estimativa enviesada ao elevar o efeito de grupos ocupacionais menores e mitigar a influência das maiores categorias. Ademais, esse procedimento estabelece nova dependência em relação às transformações que podem ocorrer com a composição por cor no decurso ao longo do tempo (Oliveira, 1997, 1998; Araújo; Ribeiro, 2002).

Dito de outra forma, o Índice de Dissimilaridade Duncan \& Duncan (D) e o Índice de Dissimilaridade Padronizado pelo Tamanho (Ds) têm limitações que impedem o controle simultâneo das mudanças na estrutura ocupacional e na composição por cor da força de trabalho, determinantes da segregação ocupacional por cor (Oliveira, 1998).

\section{3 Índice de segregação Karmel-MacLachlan (KM)}

O Índice de Karmel-MacLachlan (KM) busca superar as dificuldades que surgem ao comparar a evolução dos Índices de Dissimilaridade de Duncan \& Duncan (D) e de Dissimilaridade Padronizado Pelo Tamanho (Ds). Sinteticamente, o KM descreve a proporção de pessoas (homens brancos e homens negros) que precisam mudar de ramo de atividade econômica (com substituição), mantendo constantes a estrutura setorial e a participação (dos homens negros e dos homens brancos) no total da força de trabalho (Karmel; MacLachlan, 1988). Essa interpretação aponta o primeiro contraste entre o índice KM e os índices $\mathrm{D}$ e Ds, visto que o índice KM admite a existência simultânea da invariância, tanto na estrutura setorial quanto na composição por cor da força de trabalho. Em seguida, a equação (3) ilustra a forma de medir a segregação setorial segundo a cor: 


$$
\mathrm{KM}=\left(\frac{1}{\mathrm{~T}}\right) \sum\left|(1-\mathrm{a}) \mathrm{HB}_{\mathrm{i}}-\mathrm{aHN}_{\mathrm{i}}\right|
$$

onde:

$a=$ proporção de homens brancos no i-ésimo setor de atividade; $H B_{i}=$ número de homens brancos no i-ésimo setor de atividade; $H N_{i}=$ número de homens negros no i-ésimo setor de atividade; $T=$ total da força de trabalho.

De acordo com Karmel e MacLachlan (1988), para satisfazer o critério de invariância na estrutura setorial e de distribuição idêntica de homens brancos e homens negros na força de trabalho, após a redistribuição, é necessário ter $a T_{i}$ homens brancos e $(1-a) T_{i}$ homens negros no i-ésimo setor de atividade, onde $T_{i}=H B_{i}+H N_{i}$. Diante disso, assume-se, sem perda de generalidade, que $H B_{i}>a T_{i}\left(e H N_{i}<(1-a) T_{i}\right)$ pode ser visto como $H B_{i}-a T_{i}$ homens brancos e $(1-a) T_{i}-H N_{i}$ homens negros necessitam mudar de ramo. Noutras palavras, o número de pessoas segundo a cor que devem mudar para ou do grupo setorial é $H B_{i}-a T_{i}+(1-a) T_{i}-H N_{i}$ (Karmel; MacLachlan, 1988).

A equação (4) aponta a relação existente entre os índices KM e D:

$$
K M=2 a(1-a) D
$$

Assim, quando não há segregação, $D=0$ e $K M=0$. Se há segregação, $2 a(1-a) D \leq 0,5 D$, como o valor máximo de $D=1$, então o valor máximo de $K M=0,5$ (Salas, 2004).

De forma sucinta, o índice KM assume valores entre 0 e 0,5. $\bigcirc$ valor 0 expressa que inexiste segregação, e, pelo valor 0,5 , constata-se segregação. Com base nesses índices, analisamos a segregação ocupacional no mercado de trabalho brasileiro, no período 2002-2012.

\section{Segregação ocupacional segundo cor no mercado de trabalho brasileiro, no período 2002 a 2012}

Os estudos mencionados anteriormente ressaltam a segregação entre homens e mulheres no mercado de trabalho nacional. Tendo por base esse re- 
sultado, este artigo analisa a segregação ocupacional entre homens negros e brancos segundo nível de escolaridade no período de 2002 a 2012, bem como entre mulheres negras e brancas segundo os mesmos recortes e período.

\subsection{Segregação ocupacional entre homens e mulheres segundo cor e faixas de anos de estudo}

Conforme mencionamos, King (2009) se dedicou ao cálculo da segregação ocupacional no mercado de trabalho brasileiro. $O$ valor do Índice de Duncan entre mulheres negras e brancas em 1989 correspondeu a 0,251, reduzindo-se para 0,229 em 2001, enquanto, no caso de trabalhadores negros e brancos, esses valores foram de 0,221 para 0,23 no mesmo período. Sinteticamente, no início do intervalo estudado por King (2009), os índices $\mathrm{D}$ revelavam maior segregação ocupacional entre mulheres brancas e negras do que entre homens negros e brancos, ao passo que, no ano de 2001, esses valores são similares. Vale ressaltar que a segregação ocupacional entre mulheres negras e brancas se reduziu no mesmo período, ao passo que o índice $\mathrm{D}$, estimado para homens negros e brancos, tem ligeira elevação.

Inicialmente, estimamos os índices D, Ds e KM segundo sexo e cor no intuito de analisar as semelhanças e as diferenças em relação à segregação ocupacional no período de 2002-2012. Como se vê no Gráfico 1, os valores dos índices KM são menores em relação aos patamares dos índices $\mathrm{D}$ e Ds. ${ }^{1}$ Os índices D e KM, por sua vez, revelam maior segregação ocupacional entre mulheres brancas ou negras do que entre homens negros ou brancos; no entanto, tais valores convergem ao final do intervalo. Essa tendência para aproximação dos valores dos índices de segregação ocupacional estimados para pessoas do sexo feminino e masculino se deve sobretudo à redução nos valores dos índices $\mathrm{D}$ e KM entre as mulheres negras ou brancas.

Por outro lado, a estimativa do índice de $\mathrm{Ds}^{2}$ revela que a segregação

$1 \mathrm{O}$ índice KM se relaciona com o índice D por meio de fórmula, a saber: $2 \mathrm{a}(1-\mathrm{a}) \mathrm{D}$. Onde, "a" representa a proporção de negros no total dos ocupados. $O$ valor de "a" varia de 0 a 1 , e o valor máximo da expressão " $2 \mathrm{a}(1-\mathrm{a})$ " é, portanto, igual a 0,5 . Esse resultado pode ser obtido se igualarmos ao valor de 0 a primeira derivada dessa fórmula. Conclui-se que, em qualquer valor de $\mathrm{D}$, o índice KM será no máximo a metade de seu valor.

2 índice padronizado é mais sensível a mudanças na proporção de negras em ocupações 
ocupacional entre os homens negros ou brancos é maior do que aquela existente entre as mulheres brancas ou negras no período analisado, ainda que se verifique queda em ambos os índices. No caso das mulheres, essa redução no índice de segregação ocupacional se revela mais intensa. Ou seja, esse índice (Ds) expressa diferenças distintas na segregação ocupacional segundo sexo e cor em relação aos valores estimados pelos índices D e KM.

\section{Gráfico 1 Índices de segregação ocupacional D, Ds e KM entre mulheres negras ou brancas, bem como entre homens brancos ou negros (2002-2012)}

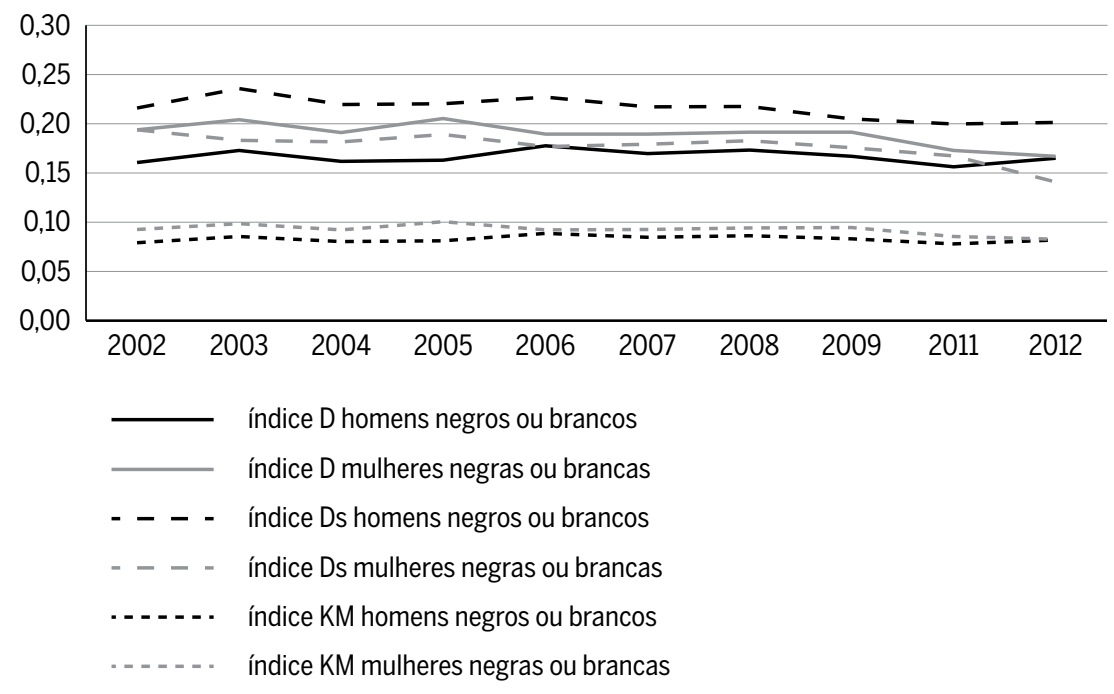

Fonte: PNAD/IBGE, 2002-2012.

Considerando esses resultados, optamos por estimar esses índices segundo sexo, cor e grupos de anos de estudo, no intuito de tornar mais homogêneos os trabalhadores e, assim, analisar mais adequadamente o patamar de segregação ocupacional.

que suas participações são menores. No caso de uma redução mais intensa da segregação nesse grupo, o índice Ds "exagera" propositadamente essa distorção. Essa virtude do índice Ds é também sua fraqueza, na medida em que enviesa os cálculos de segregação ocupacional. No cotejo da segregação ocupacional entre homens ou mulheres, notamos redução mais intensa da segregação entre as mulheres brancas ou negras nos títulos ocupacionais com menor participação relativa no total das mulheres ocupadas, enquanto entre negros ou brancos se verifica movimento oposto. 


\section{2 Índice D estimado para homens segundo cor e faixas de anos de estudo}

O Gráfico 2 revela que os valores dos índices D são análogos no início do período analisado segundo diferentes níveis de escolaridade, exceto entre homens negros e brancos que têm de 11 a 14 anos de estudo. Na maioria do período analisado, esse grupo permanece com maiores patamares de segregação ocupacional entre pessoas do sexo masculino, brancas ou negras. Nas diversas faixas de anos de estudo, os trabalhadores negros se concentram em alguns grupos ocupacionais, a saber: trabalhadores dos serviços e trabalhadores da produção de bens e serviços da reparação e manutenção. À guisa de ilustração, no ano de 2012, os negros representavam $57,6 \%$ dos trabalhadores dos serviços e $50,1 \%$ dos trabalhadores da produção de bens e serviços da reparação e manutenção. Por outro lado, a participação dos assalariados negros no total de assalariados (ocupados) correspondia a 48,5\%. Nas faixas de anos de estudo mais elevadas, reduz-se a proporção de negros, sobretudo entre as pessoas que têm 15 anos ou mais de estudo. A segregação ocupacional mais intensa entre negros ou brancos que têm de 11 a 14 anos de estudo se deve a maior participação de pessoas negras em determinados grupos ocupacionais em relação a sua participação no total dos assalariados e a menor proporção de negros entre assalariados com nível mais elevado de escolaridade.

Ao término do intervalo, os índices de segregação ocupacional entre homens brancos ou negros menos escolarizados (menos de 11 anos de estudo) se reduziram, ao passo que esses índices se elevaram, principalmente entre pessoas do sexo masculino negras ou brancas com 15 anos de estudo ou mais. Noutras palavras, o nível de escolaridade entre homens brancos ou negros se elevou no passado recente; no entanto, a segregação ocupacional também aumentou. Esses resultados apontam que a elevação do nível de escolaridade isoladamente não se mostra suficiente para mitigar tal segregação. Esse resultado pode ser proveniente da qualidade da educação a que as pessoas negras têm acesso, bem como de barreiras à mobilidade social como a discriminação segundo a cor.

O Gráfico 2 revela, portanto, redução nos patamares da segregação ocupacional de 2002 a 2012, principalmente entre as pessoas do sexo masculino brancas ou negras com baixa escolaridade (menos de 11 anos de estudo), enquanto entre homens negros ou brancos mais escolarizados (mais de 10 
anos de estudo), no mínimo o patamar da segregação ocupacional se manteve semelhante no início e no final do período. Em geral, as pessoas com menores níveis de escolaridade disputam títulos ocupacionais que exigem pouca qualificação, enquanto aqueles mais escolarizados buscam postos de trabalho que exigem pessoas mais qualificadas. Conforme mencionamos, a qualificação compreende conhecimento formal e informal (adquirido no local de trabalho), hábitos e atitudes. As famílias que têm melhor posição na escala social, por sua vez, reúnem melhores condições para transmissão de hábitos e atitudes adequadas aos seus filhos para a obtenção de um posto de trabalho qualificado. Cabe ressaltar que os maiores valores estimados dos índices $\mathrm{D}$ abarcam homens negros ou brancos mais escolarizados nesse intervalo.

Gráfico 2 Índices de segregação ocupacional D entre homens brancos ou negros segundo faixas de anos de estudo no período 2002-2012

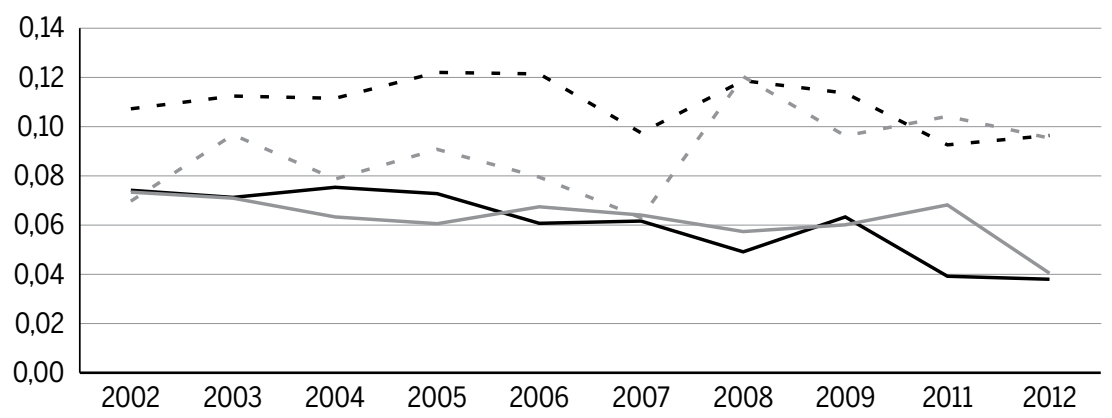

_ índice D Homens negros ou brancos com menos de 8 anos de estudo _ índice D Homens negros ou brancos que têm entre 8 e 10 anos de estudo - - - - índice D Homens negros ou brancos que têm entre 11 e 14 anos de estudo . - . - índice D Homens negros ou brancos que têm 15 anos de estudo ou mais

\section{3 Índice Ds estimado para homens segundo cor e faixas de anos de estudo}

Os valores estimados dos índices Ds para homens negros ou brancos, segundo distintas faixas de anos de estudo, mostram-se similares no início do intervalo analisado, porém os índices calculados para homens negros 
ou brancos que têm 15 anos ou mais de estudo são maiores inclusive no ano de 2002.

Gráfico 3 Índices de segregação ocupacional Ds entre homens brancos ou negros segundo faixas de anos de estudo no período 2002-2012

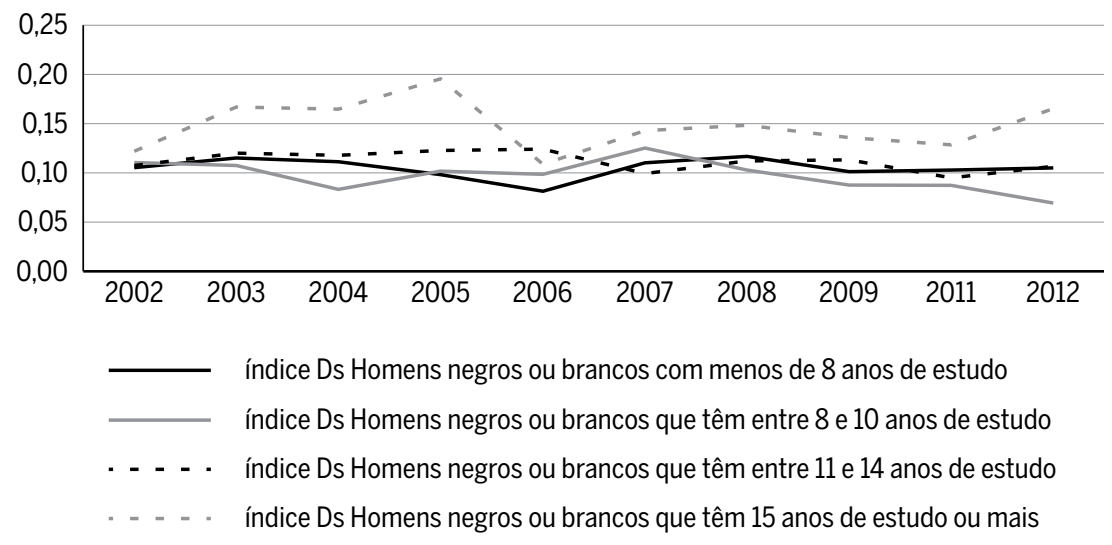

Fonte: PNAD/IBGE, 2002-2012.

Os índices estimados segundo distintos recortes apontam oscilações no período estudado. Os valores dos índices Ds para homens negros ou brancos que têm menos de oito anos de estudo e os valores daqueles que têm de 11 a 14 anos de estudo são semelhantes no início (2002) e no final (2012) do período. Ou seja, nesse grupo se nota estabilidade nos valores dos índices Ds. O patamar de segregação ocupacional entre homens que têm de 8 a 10 anos de estudo no início e no final do período se reduziu, ao passo que, para homens negros ou brancos com 15 anos de estudo ou mais, seus índices Ds são maiores ao término do intervalo. Os índices estimados, segundo distintos recortes, indicam oscilações no período estudado. Os valores dos índices Ds para homens negros ou brancos que têm menos de 8 anos de estudo e os valores daqueles que têm de 11 a 14 anos de estudo são semelhantes no início (2002) e no final (2012) do período. Ou seja, nesse grupo se verifica estabilidade nos valores dos índices Ds. O patamar de segregação ocupacional entre homens que têm de 8 a 10 anos de estudo no início e no final do período se reduziu, mas, para homens negros ou brancos com 15 anos de estudo ou mais, seus índices Ds são maiores ao término do intervalo. 


\section{4 Índice KM estimado para homens segundo cor e faixas de anos de estudo}

Como se vê no Gráfico 4, no início do período, os valores dos índices KM para homens brancos ou negros, segundo distintos grupos de estudo, têm valores análogos, exceto no caso daqueles que têm 15 anos de estudo ou mais.

Gráfico 4 Índices de segregação ocupacional KM entre homens brancos ou negros segundo faixas de anos de estudo no período 2002-2012

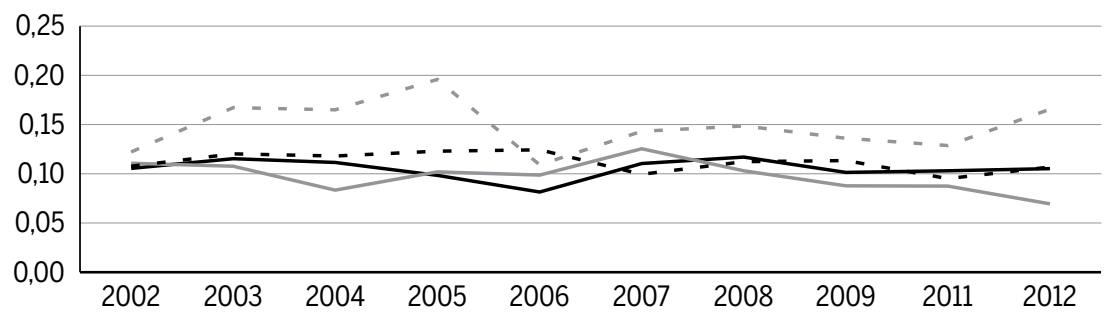

_ índice KM Homens negros ou brancos com menos de 8 anos de estudo _ índice KM Homens negros ou brancos que têm entre 8 e 10 anos de estudo

. - - . índice KM Homens negros ou brancos que têm entre 11 e 14 anos de estudo

" - - - " índice KM Homens negros ou brancos que têm 15 anos de estudo ou mais

Fonte: PNAD/IBGE, 2002-2012.

Ao transcorrer o período estudado, os índices KM analisados oscilam; todavia, os valores para pessoas do sexo masculino com 15 anos de estudo ou mais permanecem maiores. Os índices de KM estimados para homens brancos ou negros com menos de 8 anos de estudo e para aqueles que têm de 11 a 14 anos de estudo têm patamares análogos. O Gráfico 4 revela também que em vários anos os valores dos índices de KM para pessoas do sexo masculino que têm de 8 a 10 anos de estudo são os mais baixos.

De forma sintética, no princípio do intervalo analisado (2002), os valores dos índices D, Ds e KM se revelam análogos para pessoas do sexo masculino, brancas ou negras, com reduzida escolaridade. De 2002 a 2012, esses índices têm oscilação; contudo, ao final do período,se nota que seus patamares são iguais ou ligeiramente menores que os valores desses índices no início do intervalo. Por outro lado, os índices de segregação ocupacional entre as pessoas do sexo masculino mais escolarizadas, negras ou brancas, por sua vez, elevaram-se. Dito 
de outra forma, a elevação do nível de escolaridade entre essas pessoas não se traduziu em menor segregação ocupacional, visto que tais índices se elevaram. Essa segregação tem vários determinantes como a qualidade da escola frequentada pelos homens negros, a discriminação no mercado de trabalho, etc.

\section{5 Índice D estimado para mulheres segundo cor e faixas de anos de estudo}

Segundo o Gráfico 5, no ano de 2002, notamos que os valores dos índices $\mathrm{D}$ para pessoas do sexo feminino negras ou brancas segundo distintos níveis de escolaridade são diversos.

Gráfico 5 Índices de segregação ocupacional D entre mulheres brancas ou negras segundo faixas de anos de estudo no período 2002-2012

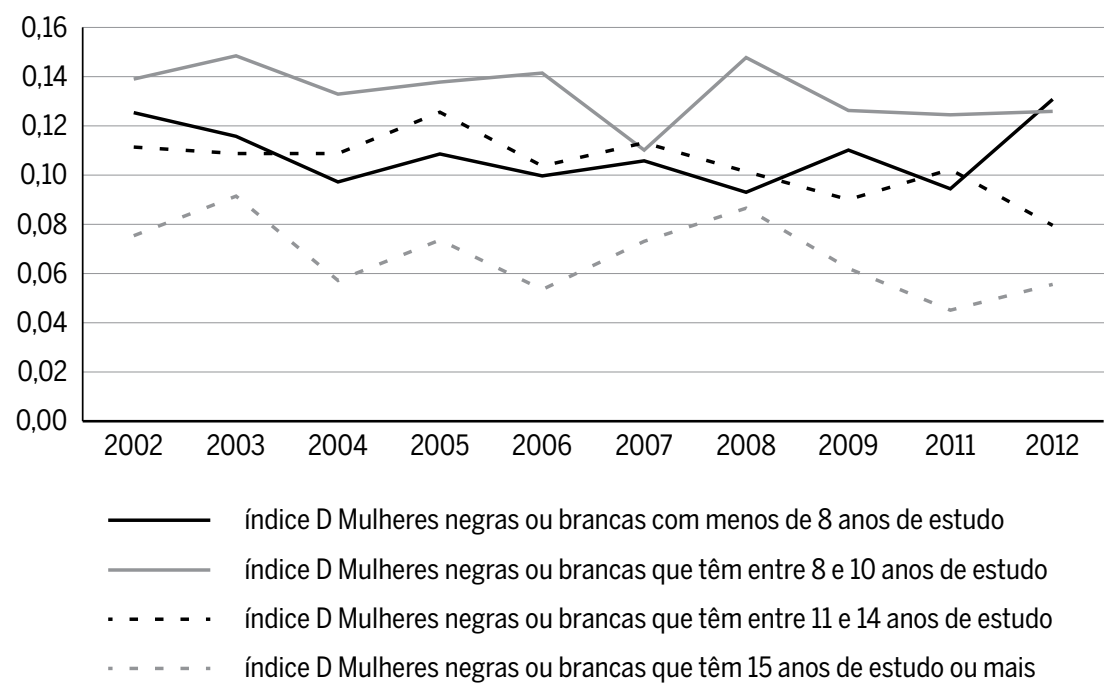

Fonte: PNAD/IBGE, 2002-2012.

Os patamares dos índices $\mathrm{D}$ se elevaram entre as mulheres com menores níveis de escolaridades (menos de 8 anos de estudo), enquanto para aquelas que têm entre 8 e 10 anos de estudo tais valores são praticamente estáveis. Por outro lado, entre as mulheres mais escolarizadas (com 11 anos ou mais de estudo), os índices D tiveram oscilação e, ao final do período, reduziram-se. 
Em suma, os valores dos índices $\mathrm{D}$ revelam que a elevação do nível de escolaridade entre pessoas do sexo feminino se conjugou com uma queda na segregação ocupacional entre essas mulheres mais escolarizadas.

\section{6 Índice Ds estimado para mulheres segundo cor e faixa de anos de estudo}

Como se percebe no Gráfico 6, no ano de 2002, os valores dos índices Ds são semelhantes entre mulheres negras ou brancas com menor nível de escolaridade (menos de 11 anos de estudo), além do que, entre essas mulheres,se notam os maiores patamares de segregação ocupacional. No intervalo analisado, tais valores têm oscilação, e, ao término desse período, a segregação ocupacional entre essas mulheres se reduziu, embora em alguns grupos de mulheres (pessoas do sexo feminino com menos de 8 anos de estudo e aquelas que têm entre 8 e 10 anos de estudo) ainda observamos os patamares mais elevados dos índices de Ds.

Gráfico 6 Índices de segregação ocupacional Ds entre mulheres brancas ou negras segundo faixas de anos de estudo no período 2002-2012

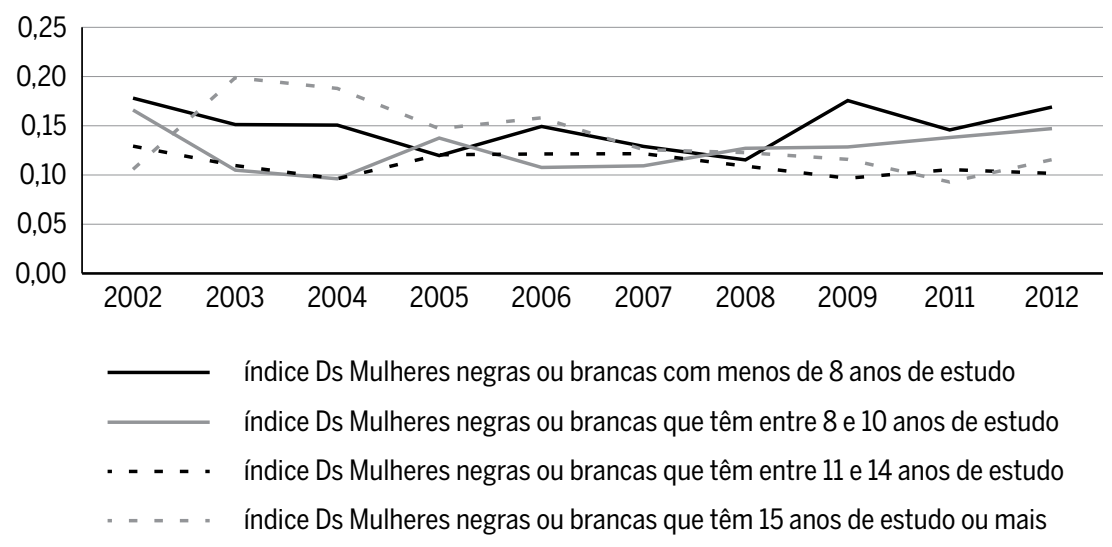

Fonte: PNAD/IBGE, 2002-2012.

Por outro lado, em 2002, o índice Ds entre mulheres negras ou brancas que têm entre 11 e 14 anos de estudo é maior do que aquele estimado entre as pessoas do sexo feminino com 15 anos de estudo ou mais. No transcorrer dos anos, verificamos que os valores desses índices Ds desses grupos de mulheres convergem. 
Em suma, os índices Ds se reduziram nos diversos grupos de mulheres negras ou brancas segundo nível de escolaridade, exceto entre as pessoas do sexo feminino com 15 anos ou mais de estudo. Os maiores patamares de segregação ocupacional se verificam entre as mulheres pouco escolarizadas. Em outras palavras, as mulheres negras com baixa escolaridade se deparam com dificuldades mais intensas em sua inserção no mercado de trabalho tal como revelam os índices Ds, ainda que se note a redução nesses valores no período.

\section{7 Índice KM estimado para mulheres segundo cor e faixas de anos de estudo}

O Gráfico 7 exibe que as mulheres negras ou brancas com menos de 8 anos de estudo e aquelas que têm entre 8 e 10 anos de estudo têm os maiores índices KM, bem como esses valores se mostram semelhantes em 2002. Ao longo do intervalo analisado, esses índices têm oscilação, ainda que, ao término do período, seus patamares permaneçam análogos aos valores do ano de 2002.

\section{Gráfico 7 Índices de segregação ocupacional KM entre mulheres brancas ou negras} segundo faixas de anos de estudo no período 2002-2012

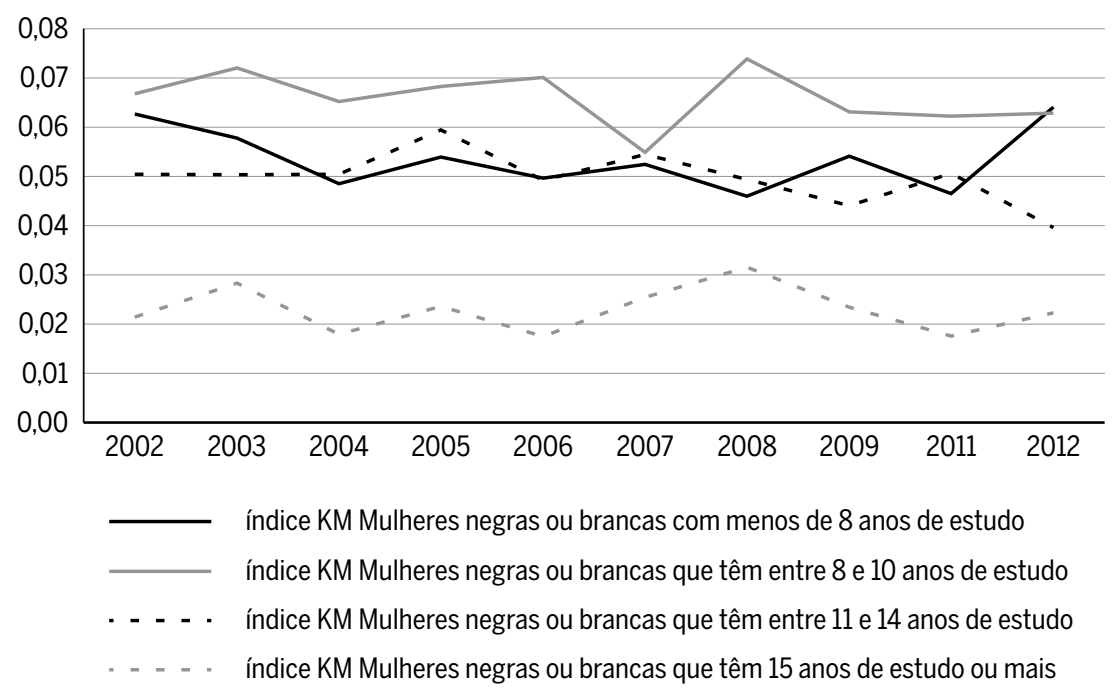

Fonte: PNAD/IBGE, 2002-2012. 
O patamar de segregação ocupacional entre as mulheres brancas ou negras que têm entre 11 e 14 anos de estudo se reduziu no período 2002-2012; no entanto, segue mais elevado que os índices de segregação ocupacional estimados para mulheres brancas ou negras com 15 anos ou mais de estudo. No grupo de mulheres mais escolarizadas (15 anos ou mais de estudo), nota-se menor patamar de segregação ocupacional.

Sinteticamente, os índices KM são maiores entre as mulheres brancas ou negras com menores níveis de escolaridade, enquanto, entre aquelas mais escolarizadas, se verifica menor patamar de segregação ocupacional.

\section{Notas conclusivas}

Os indicadores de segregação ocupacional segundo sexo no período 2002 2012 realçam a elevação dessa segregação, ainda que se note aumento do nível de escolaridade entre mulheres e homens. Esse crescimento tem vários determinantes como discriminação, preferência das mulheres por determinado posto de trabalho, etc. As razões do aumento dessa segregação será objeto de estudo de um próximo artigo. Neste estudo, optamos pela análise da segregação ocupacional segundo cor e faixas de anos de estudo.

Em relação à segregação ocupacional segundo sexo e cor, no mesmo período, os índices D e KM revelam maiores patamares de segregação ocupacional entre negras e brancas do que entre brancos e negros, ao passo que o índice Ds apontou resultado oposto. Essa divergência se deve às diferenças de metodologias entre tais índices apontadas neste artigo. No ano de 2012, os índices D e KM indicam redução nos diferenciais dos patamares de segregação ocupacional estimados entre negros ou brancos e aqueles calculados entre mulheres negras ou brancas, enquanto o índice Ds mostra maior discrepância nesses diferenciais, visto que, segundo esse índice, o patamar de segregação ocupacional entre brancas ou negras se reduziu mais intensamente. Cabe ressaltar que os índices D e KM indicam tendências similares nos patamares de segregação ocupacional entre negros ou brancos, bem como entre negras ou brancas no período de 2002-2012; vale dizer, observa-se a aproximação nos valores desses índices. Os patamares desses índices segundo sexo e cor, portanto, apontam redução nos seus diferenciais enquanto a segregação ocupacional mensurada somente a partir 
do recorte sexo se elevou no mesmo intervalo temporal. Noutras palavras, os indicadores revelam maiores dificuldades em superar os diferenciais de segregação segundo sexo do que em transpor as divergências de segregação ocupacional segundo cor dentro de cada grupo de homem ou mulher e entre esses grupos.

Focalizando os assalariados segundo cor, sexo e nível de escolaridade, nota-se que, em geral, no ano de 2002, os índices de segregação ocupacional estimados com base em tais recortes evidenciam que o patamar de segregação é maior entre mulheres brancas ou negras do que entre negros ou brancos. Ao término do intervalo, a segregação ocupacional entre brancas ou negras, que têm menos de 11 anos de estudo, ainda é mais elevada do que entre homens negros ou brancos, enquanto nas pessoas com 15 anos ou mais de estudo temos resultado oposto; vale dizer, os índices D, Ds e KM se mostram mais elevados entre as pessoas do sexo masculino com maiores níveis de escolaridade (15 anos de estudo ou mais) do que entre negras ou brancas. Dito de outra forma, a segregação ocupacional entre negros ou brancos com mais anos de estudo se intensificou, embora o nível de escolaridade também se elevou entre os homens. Esse resultado é no mínimo preocupante, visto que os homens compreendem a maioria daqueles que trabalham nos grupos ocupacionais intitulados dirigentes em geral e técnicos de nível médio. Geralmente, notamos maior proporção de homens em postos de trabalho de melhor remuneração.

Em relação aos assalariados do sexo masculino, os índices D, Ds e KM estimados para brancos ou negros segundo faixas de anos de estudo se reduziram ou permaneceram estáveis no cotejo entre os valores do ano de 2002 e de 2012, exceto entre os negros ou brancos que têm 15 anos ou mais de estudo no mesmo período. Tais índices apontam que, entre as pessoas do sexo masculino, negros ou brancos, com maiores níveis de escolaridade, se nota elevação da segregação ocupacional.

Por outro lado, os cálculos dos índices D, Ds e KM para brancas ou negras, segundo nível de escolaridade, por seu turno, indicam a redução ou a relativa estabilidade dos seus valores entre 2002 e 2012. No caso das mulheres que têm 15 anos ou mais de estudo no mesmo período, o índice de $\mathrm{D}$ aponta redução, enquanto os valores dos índices Ds e KM revelam, respectivamente, ligeira elevação e relativa estabilidade. Os maiores patamares de segregação ocupacional se verificam entre brancas ou negras com baixo nível de escolaridade (menos de 11 anos de estudo), além do 
que a elevação dos anos de estudo entre negras ou brancas não se traduziu em queda generalizada nos valores dos diferentes índices de segregação ocupacional, sobretudo entre aquelas que têm 15 anos ou mais de estudo.

Em resumo, os índices de segregação ocupacional estimado para assalariados segundo sexo, cor e nível de escolaridade apontam a elevação de seus valores entre negros ou brancos com 15 anos ou mais de estudo, enquanto, entre as pessoas do sexo feminino com mesmo nível de escolaridade, se constata relativa estabilidade ou ligeira redução nesses índices. Valendo-nos desses resultados, temos indícios de que, na concorrência entre homem branco ou negro com nível de escolaridade elevado para um posto de trabalho, tal como dirigente, provavelmente o branco tem maiores chances que o negro; no entanto, entre brancas e negras com maior nível de escolaridade, também temos indícios de maior vantagem das mulheres brancas em relação às negras, ainda que o patamar de segregação ocupacional seja menor do que entre os homens.

Desse modo, a elevação do nível de escolaridade isoladamente não reduz necessariamente a segregação ocupacional segundo sexo e cor, que, na verdade, aumentou ou se manteve estável entre as pessoas negras ou brancas com maior nível de escolaridade no passado recente. Cabe mencionar que a qualidade da educação formal a que as pessoas negras têm acesso pode contribuir para esse resultado, à medida que tais indivíduos têm maior participação entre a população pobre, que, por sua vez, tem acesso às escolas de pior qualidade. Além do que, a maior incidência da pobreza entre a população negra se conjuga com maior déficit de capitais cultural e social.

Uma saída para a redução dessa elevação da segregação ocupacional entre os mais escolarizados é a política de ação afirmativa no mercado de trabalho, além da melhora da qualidade da educação. O governo americano é pioneiro na adoção dessas medidas de combate à discriminação e à segregação. À guisa de ilustração, nos Estados Unidos, remonta aos anos 1960 a introdução, em sua legislação, de ações afirmativas no mercado de trabalho com a criação do escritório de programas federais de acatamento contratual no ano de 1965 , bem como a aprovação de leis que visam combater à discriminação, como o Título VII da Lei dos Direitos Civis. Os estudos acerca dos resultados dos programas de ação afirmativa nos EUA são controversos; contudo, podemos supor que as diferenças salariais seriam maiores se não fossem as ações do governo federal (Leonard, 1989). 
No Brasil, a Constituição Federal de 1988, no art. $7^{\circ}$, inciso XXX, proíbe a diferença de salário, de exercício de função e de critério de admissão por motivo de sexo, idade, cor ou estado civil. No entanto, os índices de segregação ocupacional apontaram que vigora a segregação ocupacional entre trabalhadores brancos(as) ou negros(as). Vale ponderar que, no Brasil, tal como nos EUA, a ausência dessa legislação estatal poderia resultar em patamares ainda mais elevados de segregação e discriminação no mercado de trabalho.

No Brasil, a adoção de programas governamentais de combate à discriminação e à segregação no mercado de trabalho pode ser importante para mitigar essa mácula do nosso mercado de trabalho. Outro caminho possível é a introdução de cláusulas de ações afirmativas nas Convenções e nos Acordos Coletivos entabulados entre sindicatos dos trabalhadores e representantes dos empregadores. Segundo estudo da OIT (2009), as Convenções Coletivas e os Acordos Coletivos firmados pela Companhia de Saneamento de Minas Gerais, pela Light S.A e pelas Centrais Elétricas de Santa Catarina (Celesc) têm cláusulas que garantem ações afirmativas. Esse estudo revela que, no ano de 2006, o contrato da Companhia de Saneamento de Minas Gerais assegurava que, em caso de empate em processo seletivo interno para cargos de confiança em que estiverem concorrendo mulheres e negros, esses trabalhadores terão acrescidos dois pontos ao total obtido na avaliação.

Em suma, ações de política afirmativa no mercado de trabalho implementadas via legislação estatal, programas governamentais específicos e cláusulas de instrumentos normativos entabulados entre sindicatos dos trabalhadores e representantes dos empresários podem contribuir para mitigar a segregação ocupacional segundo sexo e cor; todavia, deve-se ressaltar a necessidade de avaliação permanente, sobretudo dos programas governamentais.

\section{Referências}

AIGNER, D. J.; CAIN, G. C. Statistical theories of discrimination in labor markets. Industrial and Labor Relations Review, v.30, n.2, p.175-87, 1977.

ALBELDA, R. P. Occupational segregation by race and gender, 1958-1981. Industrial and Labor Relations Review, Ithaca, v. 39, n. 3, p. 404-11, 1986.

ARAÚJO, V. F.; RIBEIRO, E. P. Diferenciais de salários por gênero no Brasil: Uma análise regional. Revista Economia do Nordeste, Ceará, v. 33, n. 2, p. 1-22, abr./jun. 2002. 
BAHIA, L. D.; COELHO, D.; SILVA, A. M.; SOARES, S. A evolução da segregação por qualificação profissional ao nível das firmas. Texto para Discussão, n. 1406. Rio de Janeiro, IPEA, jun. 2009, p. 7-20. Disponível em: <http://www.ipea.gov.br/sites/000/2/publicacoes/tds/ td_1406.pdf>. Acesso em: 10 maio 2010.

BARROS, R. P.; CORSUEIL, C. H.; SANTOS, D. D.; FIRPO, S. P. Inserção no Mercado de Trabalho: Diferenciais por sexo e consequencias sobre o bem-estar. Texto para Discussao n. 796. Rio de Janeiro: IPEA, 2001. Disponível em: <http://www.ipea.gov.br/pub/td/ td_2001/td0796.pdf>. Acesso em: 2 fev. 2012.

BECKER, G. The Economics of Discrimination. Chicago University Press, 1957.

CACCIAMALI, M. C.; HIRATA, G. I. A influência da raça e do gênero nas oportunidades de obtenção de renda - Uma análise da discriminação em mercados de trabalho distintos: Bahia e São Paulo. Estudos Econômicos, São Paulo, v.35, n.4, p.767-795, out./dez. 2005.

CAIN, G. C. The challenge of segmented labor market theories to orthodox theory: A survey. Journal of Economic Literature, 14, p. 1215-1257, dez. 1976.

CAMBOTA, J. N.; PONTES, P. A. Desigualdade de rendimentos por gênero intraocupações no Brasil, em 2004. Revista de Economia Contemporânea, Rio de Janeiro, v.11, n.2, p. 331-350, maio/ago. 2007.

CHADAREVIAN, P. C. Elementos para uma crítica da teoria neoclássica da discriminação. Revista Sociedade Brasileira de Economia Política, Rio de Janeiro, n. 25, p. 104-132, 2009.

DINARDO, J.; FORTIN, N.; LEMIEUX, T. Labor market institutions and the distribution of wages, 1973-1992: A semiparametric approach. Econometrica, Chicago, v. 64, n. 5, p. 1001-1044, 1996.

EDGEWORTH, F. Y. Women's wages in relation to economic welfare. Economic Journal, p. 487-95, 1923.

EHRENBERG, R.G; SMITH, R.S. A moderna economia do trabalho. São Paulo: MAKRON Books, 2000.

GORDON, D.; EDWARDS, R.; REICH, M. Segmented work, divided workers: The historical transformation of labour in the United States. Cambridge: Cambridge University Press, 1982.

IBGE. Pesquisa de Amostra de Domicílios. CD-ROM. Microdados. Vários anos.

KARMEL, T.; MACLACHLAN, M. Occupational sex segregation - Increasing or decreasing? The Economic Record, Clayton, Australia, n. 64, p. 187-195, 1988.

KING, M. C. Occupational segregation by race and sex in Brazil, 1989-2001. USA. The Review of Black Political Economy, New York, n. 36, p. 113-125, 2009.

LEONARD, J. S. Women and affirmative action. Journal of Economic Perspectives, p. 61-75, 1989.

MADDEN, J. F. The economics of sex discrimination. Lexington, Massachusetts: Lexington Books, p. 30-36, 1973.

OIT. Negociação coletiva de trabalho e equidade de gênero e raça. Brasília: OIT, 2009. 118 p.

OLIVEIRA, Ana Maria Hermeto Camilo de. A segregação ocupacional por sexo no Brasil. 1997. 109f. Dissertação (Mestrado em Demografia) - Centro de Desenvolvimento e Planejamento Regional, Universidade Federal de Minas Gerais, Belo Horizonte, 1997. Disponível 
em:<http://www.bibliotecadigital.ufmg.br/dspace/bitstream/1843/MCCR-76AR2 B/1/ ana_maria_hermeto.pdf $>$. Acesso em: 30 abr. 2010.

OLIVEIRA, Ana Maria Hermeto Camilo de. Indicadores da segregação ocupacional por sexo no Brasil. In: ENCONTRO NACIONAL DE ESTUDOS POPULACIONAIS DA ASSOCIAÇÃO BRASILEIRA DE ESTUDOS POPULACIONAIS (ABEP), 11., 1998, Caxambu. Anais...Caxambu: ANPED, v. 1, p. 2499-2526. Disponivel em: <http://www.abep.nepo. unicamp.br/docs/anais/PDF/1998/a227.pdf>. Acesso em: $1^{\circ}$ jun. 2010.

OLSON, P. The persistence of occupational segregation: A critique of its theoretical underpinnings. Journal of Economic Issues, v. XXIV, n. 1, p. 161-70, 1990.

RIBEIRO, C. A. C. Estrutura de classes, condições de vida e oportunidades de mobilidade social no Brasil. In: HASENBALG, C.; SILVA, N. V. Origens e destinos: Desigualdades sociais ao longo da vida. Rio de Janeiro: Topbooks, 2003. p. 381-430.

SALAS, Carlos. Segregación y discriminación laboral por sexo. México: Documento de Trabajo, Departamento de Sociologia, UAM Iztapalapa, 2004. p. 1-44.

SILVA, N. V. O esquema analítico e a classificação ocupacional. In: HASENBALG, C.; SILVA, N. V. Origens e destinos: Desigualdades sociais ao longo da vida. Rio de Janeiro: Topbooks, 2003. p. 37-54.

THUROW. L. C. The economics of poverty and discrimination. Washington: Brookings Institution Press.1969.

\section{Sobre os autores}

Rosana Ribeiro-rosana.ribeiro@ufu.br

Professora associado do Instituto de Economia da Universidade Federal de Uberlândia, Uberlândia, MG.

Guilherme Silva Araújo-guilherme@dieese.org.br

Economista Dieese/SP, São Paulo, SP.

\section{Sobre 0 artigo}

Recebido em 9 de outubro de 2014. Aprovado em 15 de fevereiro de 2015. 